\title{
Preliminary Study on the Course Reform of Landscape Dendrology
}

\author{
Jiajia Fu*, Wenjun Wei \\ Nanchang Institute of Science \& Technology, Nanchang, 330108, China \\ *corresponding author
}

Keywords: Landscape Dendrology; Teaching content; Teaching reform.

\begin{abstract}
Landscape Dendrology" is one of the basic compulsory courses for landscape architecture specialty, and occupies an important position in the talents training of landscape architecture specialty. In view of the course of Landscape Dendrology in Nanchang Institute of Science and Technology, the measures and plans of teaching reform are put forward. In the past, Landscape Dendrology only emphasized theoretical study, teaching reform puts forward the combination of theory and practice to enhance students' professional practice skill level in practice, and further improve the teaching quality of course teaching.
\end{abstract}

\section{Introduction}

With the development of society and the intensification of environmental problems, taking the ecological garden road has become the focus of attention ${ }^{[1]}$. Landscape trees are the backbone material of the green space system, therefore, the cognition and application of landscape trees play a very important role in the development of gardens. Landscape Dendrology is a basic course in landscape architecture, horticulture and other related specialties. It is a vital element of landscape design, especially its ecological function, which is irreplaceable by other landscape elements. To learn the specialized course of Landscape Dendrology has important guiding significance for subsequent plant landscaping, landscape planning and design, landscape construction and so on ${ }^{[2]}$. At present, the cultivation of practical, multi-functional and high-quality new garden talents is an urgent problem for teachers of landscape architecture in the new era. Since the founding of the landscape specialty in 2014, the Nanchang Institute of Science and Technology has fully implemented the teaching reform. In combination with my years of course teaching experience, the course of Landscape Dendrology, through the joint efforts and continuous exploration of landscape architecture teachers, has made bold innovations and reforms on the teaching content, teaching methods and assessment methods, to strengthen the construction of professional training base and laboratory, to improve the quality assurance system of course teaching, and to provide reference for further improving the teaching quality of Landscape Dendrology.

\section{The Teaching Characteristics for the Course of Landscape Dendrology}

"Landscape Dendrology" is a subject to study the morphological characteristics, systematic classification, biological characteristics, ecological characteristics, geographical distribution, ornamental characteristics and garden application of garden trees ${ }^{[3]}$. It is one of the most important professional core courses in landscape architecture. It belongs to the course type of "recognition is the foundation and application is the purpose" [4] "Landscape Dendrology" has the characteristics of "numerous and complex professional terms difficult to learn and easy to forget". Through many years of teaching exploration of this course, the experience is integrated into the teaching reform, the theory is connected with the practice, and combines the characteristics of Nanchang Institute of Science and Technology and the characteristics of Landscape Architecture Specialty, based on the syllabus, it is essential to emphasize the use of teaching methods to stimulate students' interest in learning and self-learning ability in this course ${ }^{[5]}$. In order to train "solid theoretical basis, technical skills reality" of students as the goal, adapt to the needs of the teaching of Applicationoriented Undergraduate Teaching in landscape architecture, further improve and reform the 
professional courses, after several years of exploration, the teaching effect is remarkable. The learning basis and self-study of students in landscape architecture are generally weak, with participatory and situational teaching based on task, and teachers explain the key and difficult points for the course of Landscape Dendrology, and focus on arousing the enthusiasm and initiative of the students. Learning the course of Landscape Dendrology well can lay a solid foundation for students' professional learning in the future.

\section{The Program for the Course Reform of Landscape Dendrology}

\subsection{The selection of teaching materials and the optimization of course content}

Appropriate teaching materials should be selected and appropriate teaching contents should be chosen to reflect the characteristics of Application-oriented Undergraduate Education in higher education. General textbooks focus on theoretical knowledge and neglect practicality, and the content of teaching materials is deep and difficult. At present, the materials edited by the teachers of Youmin Chen, Xueying Zhuang, Juwen Sun, Jiuzhou Zhao, Guojin Qiu and so on are mainly teaching materials for Landscape Dendrology. Among them, the "Landscape Dendrology" edited by Jiuzhou Zhao is the teaching materials used for landscape architecture specialty in Nanchang Institute of Science and Technology. It is composed of general theory, training guidance and common tree branches and leaf retrieval tables. The content and the way of writing are concise with clear primary and secondary contents. The textbook gives a comprehensive explanation of the main tree species and representative tree species, and the theoretical knowledge is detailed.

According to the specific learning situation of the landscape architecture students in Nanchang Institute of Science and Technology, the book's degree of difficulty is more appropriate, but in the teaching, professional terms of garden trees for students are difficult to understand. In combination with the situation, several teachers in the garden compiled a set of teaching notes, and explained in detail the recognition characteristics of common garden trees, and the application of search tables. According to the students' learning progress, set up the corresponding course practice activities, including the field investigation and research of campus and park, writing the survey report and the plant list of the research area, tree identification for the students in the field and etc. Through practice, professional theory knowledge is more easily grasped and understood by students. The course of Landscape Dendrology is guided by the demand of talents, and students have mastered the new trend of the development of gardens in recent years, and are familiar with the plant materials and landscaping methods commonly used in plant landscaping. In addition, combined with the opinions and suggestions of industry experts and front-line technicians, the talents training system of landscape architecture specialty has been established. According to the course characteristics of "Landscape Dendrology", the course content is integrated to change the learning style of the past teaching materials, which is based on tree branches and units. Combined with the general situation of the profession, the course contents can be divided into three major items according to the application characteristics of the industry: arbors, shrubs, and woody vines. The identification and test are set up under different projects, and this teaching is more in line with the practical consideration when choosing trees in practical production.

\subsection{The reform of teaching methods}

Reform in teaching methods is an important part of deepening the reform of education and teaching. According to different characteristics of the specialty and the course, innovative teaching methods have been found, and the effect of participatory teaching, situational teaching and task teaching is realized in the teaching of this course. The combination of classroom teaching and extracurricular activities can encourage students to learn and participate actively, complete the task in the group, and improve and strengthen the students' professional quality and team cooperation ability.

Taking the actual application scene as the core, setting up the corresponding teaching situation, advocating the teaching method of "taking learning as the base, taking learning as the application", 
strengthening the actual combat skills, supplemented by the actual enterprise test project and the mode of role simulation, the whole teaching process is carried out through the gradual deepening of the teaching method. The use of landscape tree retrieval method is to cultivate students' ability to collect, process, analyze and solve problems. Through project practice, classroom discussion, online learning and professional quality training, students can set up the task goal setting, personal time management, team cooperation and communication to improve the students' professional quality. In the course of teaching, students in groups, through the means of technical research, practical operation and so on, cooperate to complete teaching tasks and projects, so as to enhance students' teamwork ability. In order to expand the students' professional knowledge and traditional learning concept, experimental and practical training shall be carried out in the course of teaching, to cultivate the students' practical ability, and accumulate professional experience for the future graduation work. Landscape Dendrology is a natural plant identification course, and the identification of tree form is the main content of landscape architecture, which is also one of the important knowledge that can be connected with the later planning and design courses ${ }^{[6]}$. In the course content setting, the practice training contents such as recognition and application of common plants on campus and other places have been added. In addition, encourage students to go out of the classroom, to the campus, park and other places to inspect and identify various common garden trees, especially the woody plants, to make plant names, display and make the process of garden specimens and so on in groups and in the form of PPT. This course emphasizes the basic knowledge of garden plants through participatory, situational, task and other teaching methods, and pays more attention to the training of tree recognition, collocation training and garden application.

\subsection{The reform of course evaluation system}

Practical skills are more important than pure theories in application-oriented undergraduate education. Therefore, reasonably design evaluation system of the teacher and student plays an important role in changing the fact with little attention on practice and emphasis on theory. In order to enrich the students' extracurricular life and broaden the depth and breadth of the students' professional knowledge, the extracurricular life of students is enriched by the implementation of the phased assessment, the final assessment, the second classroom and the innovative entrepreneurship studio. The effect evaluation is divided into three aspects.

\subsubsection{Phased assessment:}

(1)In class teaching, phased tasks are arranged and phased assessment is carried out, taking the group as the unit, students are required to make PPT according to the completion of the specific task and report the results in the form of group, teachers and groups score on the report group (the report group does not need to score their own group), the scores of the teachers and groups are counted into the group. Through the phased learning test, the habits, characteristics and landscape application of arbors, shrubs and woody vine trees can be grasped step by step.

(2) Grade composition:

In the process of task completion by the group, the group performance, individual answer and task completion are separately added, and attendance records are included in the personal scores, usually scores accounts for $40 \%$, among of them, the group task in phased test accounts for $20 \%$, the homework accounts for $10 \%$, and attendance accounts for $10 \%$.

(3) Task - based investigation:

Course learning is carried out through teams in the form of tasks, on the one hand, to train students' teamwork ability, on the other hand, to master professional knowledge in the classroom and out of class in order. In the classroom course, the learning of the theory of garden trees and the relevant practical training tasks can be completed. In the course of extracurricular activities, the second classes of the community and the creative studio are combined to carry out professional activities, make specimens and carry out art processing and innovation, and form products for display and sale. Through a period of exploration, the form effect is remarkable. On the one hand, the product can train the students' practical ability, and enhance the students' interest in learning. On the other hand, the product can increase the students' income and learn the self-confidence of 
professional knowledge.

\subsubsection{Final examination:}

At the end of the course, students are required to combine the knowledge they have learned to carry out a final project assessment. The purpose of the project assessment is to promote the students to master more garden trees and garden applications, and to take into account the usual results. Students are required to take the final exam combined with their knowledge. The final exam results accounts for $60 \%$, together with routine results of the team and personal routine scores, which constitute the final result of the individual. In the final examination, a written test is used to test the students' knowledge of the theory and the actual species of the tree, so as to promote students to grasp the theoretical knowledge and professional skills, and to lay the foundation for the future career needs.

\section{The effect of course reform}

To explore and reform the methods of teaching contents, in the selection of the course content, great importance to the study of the basic knowledge, basic configuration principles and techniques, and special terms of the garden trees shall be attached for students, so that students can master the configuration of garden trees, the morphological features of garden trees, and the application of garden, and so on. The practice of a project through phased task, students' ability of tree identification has been significantly improved, and the selection and collocation of tree species in plant landscape matching have been recognized. The spare time and the second classroom are applied to carry out the practical activities of the course, which lays a good foundation for the future study of landscape architecture, garden planning and design, landscape architecture and other courses. Through the reform and innovation of the course content system structure, the students' professional ability to understand the common garden trees correctly is deeply cultivated, which breaks the mode that the course teaching is too dependent on the teaching materials and the simple mode, and strives to achieve the goal of "practical, applied, and useful" curriculum construction.

\section{Acknowledgements}

The science and technology research project of Jiangxi Provincial Education Department (GJJ151237); the science and technology project of Nanchang Institute of Science and Technology (GJKJ-15-20); the science and technology project of Nanchang Institute of Science and Technology (GJKJ-15-21); the science and technology project of Nanchang Institute of Science and Technology (GJKJ-15-22); the science and technology project of Nanchang Institute of Science and Technology (GJKJ-15-23).

\section{References}

[1] Zhihui Liang. Thoughts on improving urban greening and building eco city [J]. Henan science and technology 2015, (11): 86.

[2] Mingyun Du, Dekui Zang, Xianfeng Guo. Preliminary study on teaching reform of experimental and practical courses of Landscape Dendrology in landscape architecture [J]. Laboratory teaching, 2008. (4): 38 - 39.

[3] Dongmei Yao, Shaorong Wang. Discussion on the teaching method of Landscape Dendrology. [J]. Forum on science and technology (second half month), 2010 (9), 166- 167.

[4] Daqiu Zhao, Jiasong Meng. Reform and practice on multimedia teaching in the course of Landscape Dendrology [J]. Anhui Agricultural Sciences, 2015, 43 (15): 379 - 380+383.

[5] Guojin Qiu. Landscape Dendrology [M]. Beijing: China Agriculture Press, 2006.

[6] $\mathrm{Na}$ E, Kaiyun Wei. Discussion on the existing problems in the teaching of Landscape Dendrology [J]. Modern horticulture, 2016 (4):140 - 141. 